\title{
$R$-Curve Determination of 3Y-PSZ by the Indentation Strength-in-Bending Method
}

\author{
Jing-Feng LI, Akira KAWASAKI and Ryuzo WATANABE \\ Department of Materials Processing, Faculty of Engineering, Tohoku University, Aramaki-aza-Aoba, Aoba-ku, Sendai-shi 980-77
}

\author{
圧子圧入/曲げ強度法による 3Y-PSZ のR カーブ測定 \\ 李 敬鋒・川崎 亮・渡辺龍三 \\ 東北大学工学部材料加工学科, 980-77 仙台市青葉区荒巻字青葉
}

\begin{abstract}
$R$-curve in $3 \mathrm{~mol}_{\%} \mathrm{Y}_{2} \mathrm{O}_{3}$-partially stabilized $\mathrm{ZrO}_{2}$ (3Y-PSZ) ceramics was measured using the indentationstrength-in-bending method proposed by Krause, and the influence of subcritical crack growth on the $R$ curve determination was investigated. It was found that Krause's method can be used to determine conveniently the $\boldsymbol{R}$-curve in $3 \mathrm{Y}$-PSZ ceramic. In addition, the present study provided useful information about subcritical or slow crack growth from indented cracks, which was found to be remarkable during bend testing in air even at relatively high cross-head speeds when no care was taken to keep the indentation crack out from moisture.

[Received June 14, 1996; Accepted November 12, 1996]
\end{abstract}

Key-words : Crack growth resistance, R-curve, Vickers indentation, Subcritical crack growth, Partially stabilized zirconia, Environmental effect

\section{Introduction}

Much recent attention has been paid to the phenomenon of increasing crack growth resistance with crack extension, namely rising $R$-curve behavior. Ceramics having such a property are considered to be more tolerant of existing processing-defects and surface damages in service. ${ }^{1), 2)} R$ curves have been determined by using conventional techniques, ${ }^{3), 4)}$ for example, the compliance method employing notched beam specimens. In such experiments, the growth of a precrack can be stably controlled so that the crack can be traced continuously or stepwisely during loading and unloading cycles, and the fracture resistance pertaining to a given crack size can therefore be computed. Recently, it has been shown that the indentation strength-inbending (ISB) method can be applicable to the $R$-curve determination according to the detailed analysis by Krause. ${ }^{5)}$ Compared with the conventional compliance methods, Krause's method can be utilized conveniently even without special instruments and matured experimental experiences as required for the compliance methods.

By the compliance method it has been revealed that partially stabilized zirconia (PSZ) ceramics exhibit rising $R$ curve behavior due to the well-known stress-induced phase transformation toughening effect in the vicinity of the propagating cracks. ${ }^{6), 7)}$ In the present study, Krause's method was applied to the determination of $R$-curve in 3 mol\% $\mathrm{Y}_{2} \mathrm{O}_{3}$-partially stabilized $\mathrm{ZrO}_{2}$ ceramics, which possess well combined mechanical properties of high strength and relatively good fracture toughness among a series of PSZ ceramics. The preliminary experiment showed that loading rate affected the $R$-curve determination, which was gradually confirmed to be caused by the subcritical crack growth (SCG) during measuring the failure stresses of the indented specimens. Therefore, the motivation for this paper was to clarify the SCG behavior of indentation cracks during the $R$-curve determination by Krause's method.

\section{Experimental procedure}

\subsection{Sample preparation}

The starting material used in this work was $3 \mathrm{~mol} \%$ $\mathrm{Y}_{2} \mathrm{O}_{3}$-partially stabilized zirconia powder (Tosoh Corporation, Tokyo, Japan). The powder was pressed into plates at $100 \mathrm{MPa}$ by using hardened tool steel dies. The green plates were isostatically cold-pressed at $200 \mathrm{MPa}$ and then sintered to almost full density at $1450^{\circ} \mathrm{C}$ for $4 \mathrm{~h}$ in air. Bend specimens of nominal dimensions $24 \mathrm{~mm} \times 4 \mathrm{~mm} \times 2 \mathrm{~mm}$ were cut with diamond blades. The prospective tensile surfaces were finally diamond-polished to achieve a mirrorlike surface finish prior to mechanical testing. No monoclinic phase was detected on the polished surface by X-ray diffraction analysis.

\subsection{Determination of $R$-curve}

According to the analysis by Krause, ${ }^{5)} R$-curve can be presented by a power-law function of the fracture toughness / resistance, $K_{\mathrm{R}}$, versus the crack extension, $\Delta c$ :

$$
K_{\mathrm{R}}=k(\Delta c)^{m}
$$

where $k$ and $m$ are material-dependent constants. They can be obtained on the basis of a logarithmic plot of the bending strength $\left(\sigma_{\mathrm{m}}\right)$ of the indented specimen as a function of the indentation load $(P)$ :

$$
\sigma_{\mathrm{m}}=\alpha P^{-\beta} \text { or } \log \sigma_{\mathrm{m}}=\log \alpha-\beta \log P
$$

Using the values of $\alpha$ and $\beta$ determined by the above equation, the parameters defining the $R$-curves, $k$ and $m$, can be computed as follows

$$
\begin{aligned}
& m=(1-3 \beta) /(2+2 \beta) \\
& k=Y \alpha(\beta \gamma)-\beta(1+\beta)^{(1+\beta)}
\end{aligned}
$$

where $Y$ is a dimensionless configuration coefficient with an approximate value of 1.17 for the present experiment. ${ }^{5)}$ The constant $\gamma$ is related to the initial crack length $\left(c_{\mathrm{i}}\right)$ of as-indented crack and the indentation load $(P)$ as follows $\gamma=P / c_{i}^{2 /(1+\beta)}$

For the experiment, three Vickers indentations of the same load were generated, each about $2 \mathrm{~mm}$ apart, on the tensile surface area corresponding to the inner span of the bending test, as shown in Fig. 1. Special care was taken to ensure that one diagonal of the indentation impression was aligned perpendicular to the tensile stress direction. The failure stress of the indented specimen was measured in a 4point bending test with $20 / 10 \mathrm{~mm}$ spans using a universal testing machine (INSTRON 4204). The bend testing was conducted in air (50-60\% relative humidity) and in a vacuum chamber $\left(<1.3 \times 10^{-3} \mathrm{~Pa}\right)$ at different cross-head speeds of $0.1,0.5$ and $5 \mathrm{~mm} / \mathrm{min}$. For the bend testing in vacuum, a drop of silicone oil was placed on the indentations immediately after unloading the indenter, to minimize effects from moisture-assisted crack growth, while such 
(A)

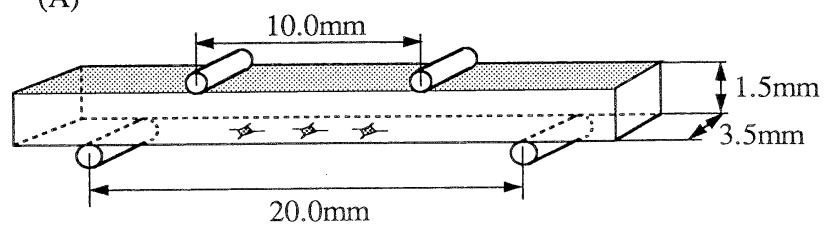

(B)

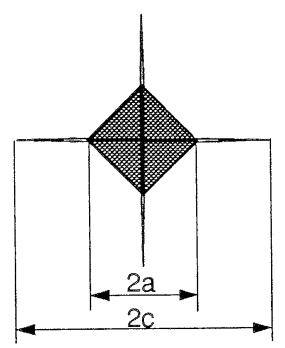

Fig. 1. Schematic drawing of the indentation strength-in-bending method used for the $R$-curve determination in the present study: (A) 4-point bending test with Vickers indentations, (B) detail of indentation mark.

treatment was not intentionally given to the specimen to be tested in air. Three measurements were run to obtain an average value of failure stress with the same indentation, even though the data scattering was finally found to be very small. It was confirmed that the bend specimens were all broken from one of the three indentations. The surviving two "dummy" indentations were used to measure the final length $\left(c_{\mathrm{f}}\right)$ of the indentation cracks at the time of fracture. The initial and final crack sizes were measured with an optical microscope connected to an image analyzer at 200 magnifications.

\section{Results and discussion}

The results of the indentation-bend testing are presented in Fig. 2, by plotting the logarithm of failure stress versus the logarithm of indentation load. Each set of data was well fitted by the linear least-square method to a line with a slope $<1 / 3$, indicating that rising $R$-curve behavior exists in the $3 Y-P S Z$ ceramics. However, the failure stress shifted up with increasing cross-head speed when the indented specimen was fractured in air, but the value obtained in vacuum was almost the same for the same indentation load. This result suggested the possibility that subcritical or slow crack growth from the indented crack occurred due to the effect of moisture in the specimens tested in air, since decreasing the cross-head speed led to the decrease in failure stress.

The subcritical crack growth was confirmed by comparing the final length $\left(c_{\mathrm{f}}\right)$ of the surviving "dummy" indentations for the specimens tested in air and in vacuum. Figure 3 shows two sets of representative data for the specimens with the indentations of the same $98 \mathrm{~N}$ load. The initial crack length $\left(c_{\mathrm{i}}\right)$ determined by the indentation load was the same, being equal to $136 \mu \mathrm{m}$, while the crack extended longer with decreasing cross-head speed when the influence of moisture on the indentation crack was not intentionally suppressed. When the cross-head speed was 0.1 $\mathrm{mm} / \mathrm{min}$, the crack extended about $375 \mu \mathrm{m}$ during testing in air. The crack extended about $50 \mu \mathrm{m}$ even in vacuum probably due to "critical" stable crack growth resulting from rising $R$-curve behavior, which is totally different from the subcritical crack growth. By using the failure stress and Young's modulus (220 GPa) and the dimensions of bend bar, the testing time was estimated to be about $23 \mathrm{~s}$ for the $98 \mathrm{~N}$-indented specimen tested at $0.1 \mathrm{~mm} / \mathrm{min}$. Thus, the
Indentation load, P / N
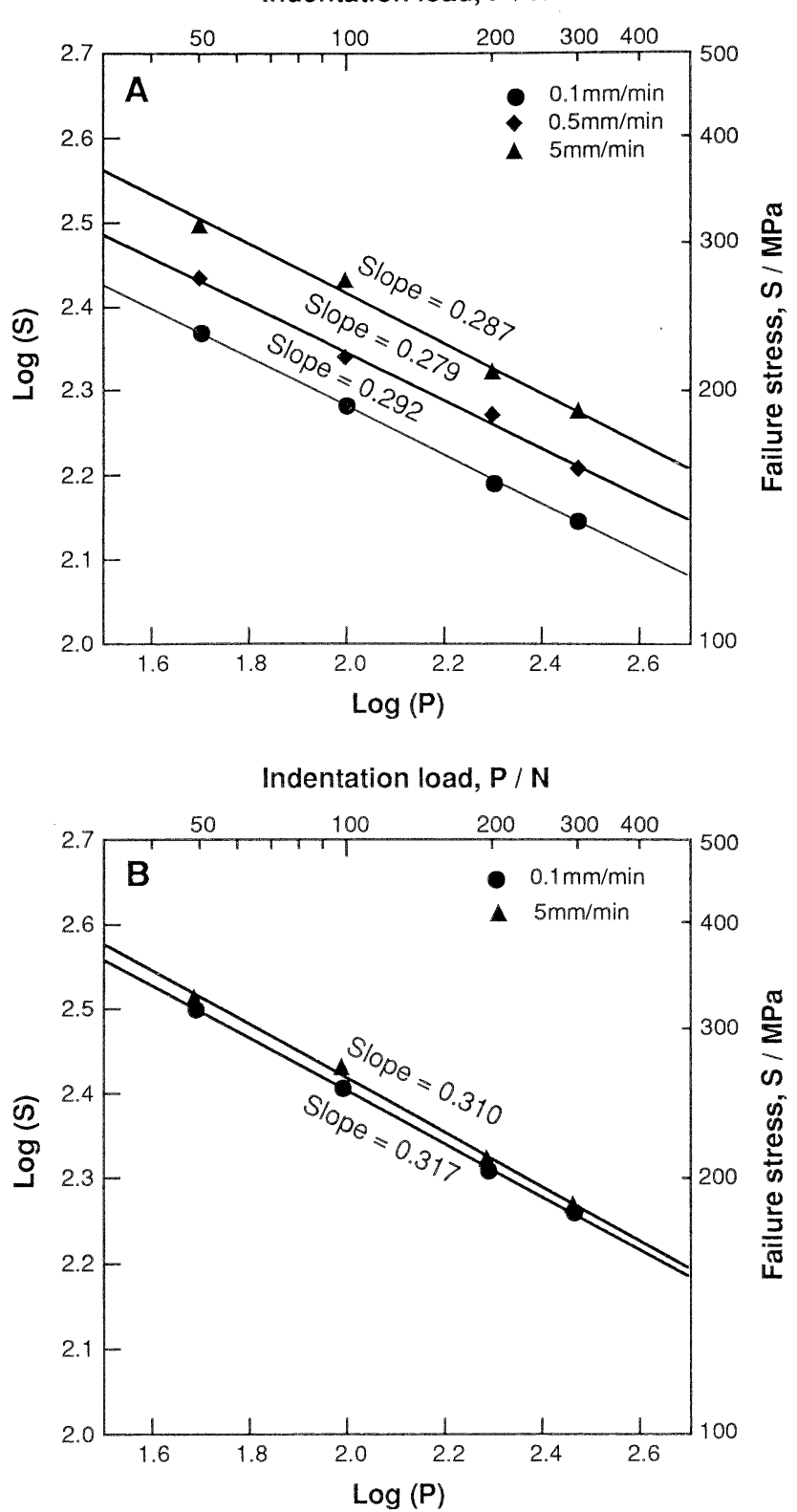

Fig. 2. Logarithmic plot of failure stress versus indentation load for the indented specimens, on the basis of the data in air (A) and in vacuum (B) at the shown cross-head speeds. The symbols are the experimental data and the lines are linear least-square fits.

average value of subcritical crack growth speed was about $1.6 \times 10^{-5} \mathrm{~m} / \mathrm{s}$, falling in the order of the reported values. ${ }^{8)}$ Therefore, it is easy to explain why the decrease in crosshead speed resulted in the decrease in failure stress by associating the failure stress data with the final crack length $\left(c_{f}\right)$ for the bend testing in air. In other words, since the crack of the final length $\left(c_{\mathrm{f}}\right)$ caused the fracture of the bending specimen, the larger the crack the lower the failure stress.

When the cross-head speed was as high as $5 \mathrm{~mm} / \mathrm{min}$ the influence of subcritical crack growth was almost negligible, since the failure stresses and the final crack length were the same as those obtained in vacuum. The $R$-curves were determined by using the indentation-bending data almost without the influence of the subcritical crack growth, i.e., in air at the cross-head speed of $5 \mathrm{~mm} / \mathrm{min}$ and in vacuum at the two speeds. Figure 4 shows the computed $R$-curves according to the procedure described in the experimental sec- 


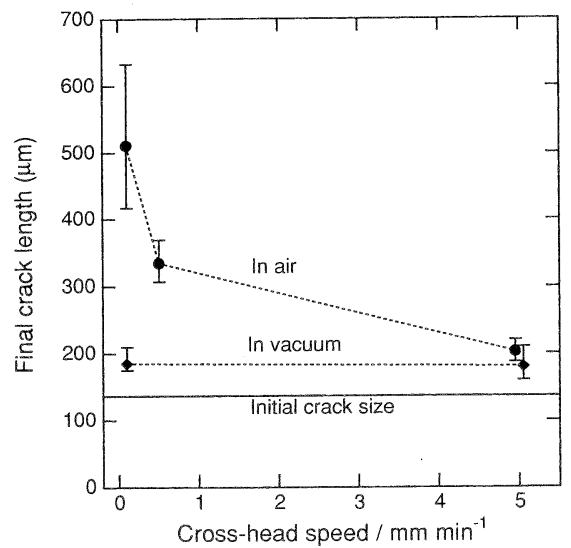

Fig. 3

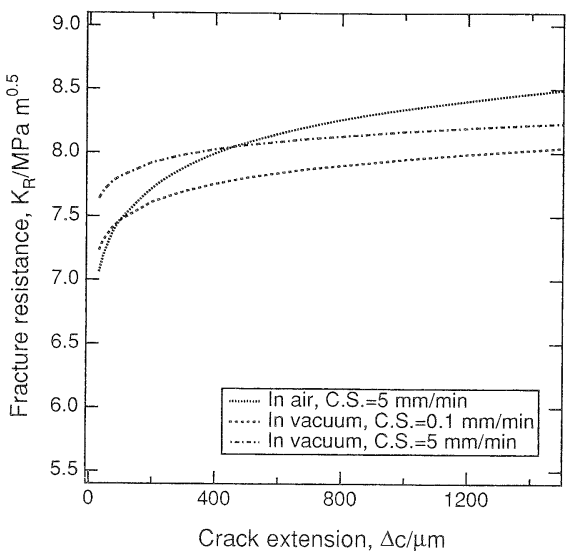

Fig. 4

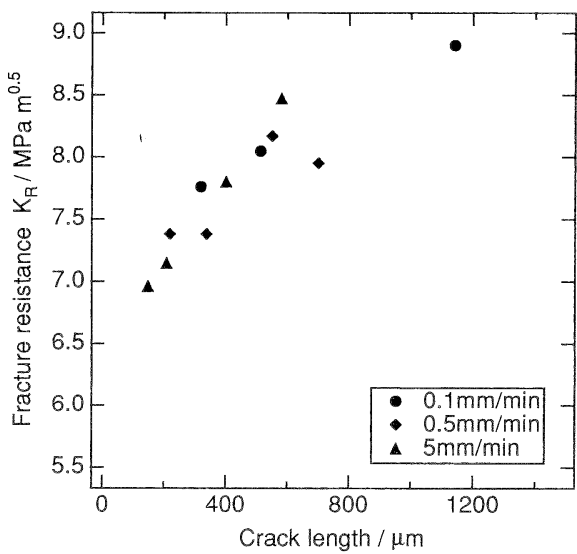

Fig. 5

Fig. 3. Variation in final crack length at the time of fracture as a function of cross-head speed for the bending test in air and in vacuum.

Fig. 4. $R$-curves of the 3Y-PSZ ceramic determined by the indentation strength-in-bending method on the basis of different data shown in Fig. 2.

Fig. $5 R$-curve obtained by relating failure stress to final crack length including subcritical crack growth occurring during testing in air.

Table 1. Parameters Defining the R-Curve in 3 Y-PSZ by the ISB Method

\begin{tabular}{c|c|c|c|c|c}
\hline \multirow{2}{*}{ Testing condition } & \multicolumn{5}{|c}{ Parameter } \\
\cline { 2 - 6 } & $\beta$ & $\log \alpha$ & $\log \gamma$ \# & $\mathrm{m}$ & $\mathrm{\kappa}$ \\
\hline $\begin{array}{c}\text { Air } \\
\text { (C.S. }=5 \mathrm{~mm} / \mathrm{min})\end{array}$ & 0.292 & 3.001 & 7.97 & 0.047 & 11.64 \\
\hline $\begin{array}{c}\text { Vacuum } \\
(\text { C.S. }=0.1 \mathrm{~mm} / \mathrm{min})\end{array}$ & 0.310 & 3.023 & 7.89 & 0.027 & 9.58 \\
\hline $\begin{array}{c}\text { Vacuum } \\
(\text { C.S. }=5 \mathrm{~mm} / \mathrm{min})\end{array}$ & 0.317 & 3.052 & 7.86 & 0.019 & 9.31 \\
\hline (\# averaged value at different indentation loads of 49 to $294 \mathrm{~N}$, C.S.= cross-head speed)
\end{tabular}

tion by using a power-law function of the fracture resistance versus the crack extension. Table 1 summarizes all the important parameters needed for the computation of $R$-curves. The $3 \mathrm{Y}$-PSZ ceramic showed rising $R$-curve behavior, that is, the fracture resistance increases with the crack growth in the initial stage of crack extension. The predominant mechanism to generate the rising $R$-curve should be the stress-induced phase transformation, whose contribution increases as the transformed zone behind the crack tip expands with crack extension. ${ }^{9), 10)}$ However, the $R$-curve in 3 Y-PSZ is not so steep as those in other toughness-optimized zirconia ceramics. ${ }^{7), 11)}$

On the other hand, since the final crack length $\left(c_{\mathrm{f}}\right)$ was already measured in the present study, it is ready to estimate the fracture resistance at the time of fracture from the failure stress $\left(\sigma_{\mathrm{m}}\right)$ using the following equation proposed by Cook and Lawn. ${ }^{12)}$

$$
K_{\mathrm{R}}=A \sigma_{\mathrm{m}} c_{\mathrm{f}}^{1 / 2}+B
$$

where $A$ and $B$ are constants experimentally decided to be 2.02 and $-0.68 \mathrm{MPa} \cdot \mathrm{m}^{0.5}$, respectively. Figure 5 shows the fracture resistance calculated by the above equation as a function of crack length. Interestingly, this method also gave a rising $R$-curve for the 3Y-PSZ ceramic.

It should be noted that the ISB method is established on the basis of median indentation crack. Strictly, this method is not suitable for evaluating $R$-curve in the present materials because its indentation crack was not exactly such a type, as also reported in other investigations. ${ }^{13), 14)}$ Nevertheless, it is considered that the $R$-curve was adequately determined by the ISB method in the present study by comparing the $R$-curves determined by the ISB method with the result of Fig. 5.

\section{Summary}

The indentation strength-in-bending (ISB) method can be used to determine conveniently the $R$-curve in $3 \mathrm{~mol} \%$ $\mathrm{Y}_{2} \mathrm{O}_{3}$-partially stabilized $\mathrm{ZrO}_{2}$ ceramics by measuring the failure stress of the indented specimens at a set of load. The present study clearly shows that subcritical or slow crack growth from the indented crack may remarkably be incurred during bend testing even at relatively high crosshead speed $(0.1-5 \mathrm{~mm} / \mathrm{min})$. To minimize the influence of subcritical slow crack growth on the $R$-curve determination by the ISB method, a cross-head speed higher than $5 \mathrm{~mm} /$ min is recommended, otherwise a measure should be taken to keep the indentation crack out from moisture.

\section{References}

1) M. P. Harmer, H. M. Chan and G. A. Miller, J. Am. Ceram. Soc., 75, 1715-28 (1992).

2) A. G. Evans, J. Am .Ceram. Soc., 73, 187-206 (1990).

3) G. Vekinis, M. F. Ashby and P. W. R. Beaumont, Acta Metall. Mater., 38, 1151-62 (1990).

4) E. H. Lutz, N. Claussen and M. V. Swain, J. Am. Ceram. Soc., 74, 11-18 (1991).

5) R. F. Krause, Jr., J. Am. Ceram. Soc., 71, 338-43 (1988).

6) M. V. Swain and R. H. J. Hannik, "Advances in Ceramics, Vol. 12, Science and Technology of Zirconia II", Ed. by N. Claussen, M. Rühle and A. H. Heuer, American Ceramic Society, Columbus (1984) pp. 225-40.

7) S. Srinivasan and R. O. Scattergood, J. Mater. Res., 5, 149095 (1990)

8) J. Chevalier, C. Olagnon, G. Fantozzi and B. Cales, J. Am. Ceram. Soc., 78, 1889-94 (1995).

9) D. J. Green, H. J. Hannink and M. V. Swain, "Transformation Toughening of Ceramics", CRC Press (1989) pp. 57-96.

10) R. M. McMeeking and A. G. Evans, J. Am. Ceram. Soc., 65 242-46 (1982).

11) P. F. Becher and W. H. Warwick, J. Am. Ceram. Soc., 77, 2689-92 (1994).

12) R. F. Cook and B. R. Lawn, J. Am. Ceram. Soc., 66, C200-01 (1983).

13) M. Ashizuka, H. Kiyohara, E. Ishida and M. Kuwabara, Y. Kubota and T. Tsukidate, Yogyo-Kyokai-Shi, 94, 1049-55 (1986).

14) M. S. Kaliszewski, G. Behrens, A. H. Heuer, M. C. Shaw, D. B. Marshall, G. W. Dransmann, R. W. Steinbrech, A. Pajares, F. Guiberteau, F. L. Cumbrera and A. DominguezRodriguez, J. Am. Ceram. Soc., 77, 1185-93 (1994). 